\title{
PIEZO1 Channel Is a Potential Regulator of Synovial Sarcoma Cell-Viability
}

\author{
Takahisa Suzuki ${ }^{\dagger}$, Yukiko Muraki ${ }^{\ddagger}$, Noriyuki Hatano ${ }^{\ddagger}$, Hiroka Suzuki ${ }^{\ddagger}$ and \\ Katsuhiko Muraki *,t,
}

Laboratory of Cellular Pharmacology, School of Pharmacy, Aichi-Gakuin University, 1-100 Kusumoto, Chikusa, Nagoya 464-8650, Japan; c172903@ed.nagoya-cu.ac.jp (T.S.); ymuraki@helen.ocn.ne.jp (Y.M.);

nhatano@dpc.agu.ac.jp (N.H.); hsuzuki@dpc.agu.ac.jp (H.S.)

* Correspondence: kmuraki@dpc.agu.ac.jp; Tel.: +81-52-757-6788

t These authors contributed equally to this work.

$\ddagger$ These authors contributed equally to this work.

Received: 14 April 2018; Accepted: 10 May 2018; Published: 14 May 2018

\begin{abstract}
Detection of mechanical stress is essential for diverse biological functions including touch, audition, and maintenance of vascular myogenic tone. PIEZO1, a mechano-sensing cation channel, is widely expressed in neuronal and non-neuronal cells and is expected to be involved in important biological functions. Here, we examined the possibility that PIEZO1 is involved in the regulation of synovial sarcoma cell-viability. Application of a PIEZO1 agonist Yoda1 effectively induced $\mathrm{Ca}^{2+}$ response and cation channel currents in PIEZO1-expressing HEK (HEK-Piezo1) cells and synovial sarcoma SW982 (SW982) cells. Mechanical stress, as well as Yoda1, induced the activity of an identical channel of conductance with $21.6 \mathrm{pS}$ in HEK-Piezo1 cells. In contrast, Yoda1 up to $10 \mu \mathrm{M}$ had no effects on membrane currents in HEK cells without transfecting PIEZO1. A knockdown of PIEZO1 with siRNA in SW982 cells abolished Yoda1-induced $\mathrm{Ca}^{2+}$ response and significantly reduced cell cell-viability. Because PIEZO1 is highly expressed in SW982 cells and its knockdown affects cell-viability, this gene is a potential target against synovial sarcoma.
\end{abstract}

Keywords: PIEZO1; Yoda1; synovial sarcoma; mechanical stress; cell-viability

\section{Introduction}

Detection of mechanical stress is essential for diverse biological functions including touch, audition, and maintenance of vascular myogenic tone. In the latter, shear stimuli into vascular endothelial cells can activate various endothelial ion channels and subsequently affect vascular functions. Therefore, mechano-sensors in the endothelium are important regulators of blood pressure, arteriosclerosis, and vascular remodeling. We and others have recently identified that vascular endothelial cells express PIEZO1, a mechano-sensing cation channel that regulates vascular development in neonatal mice [1,2]. Because PIEZO1 is widely expressed in neuronal and non-neuronal cells, we anticipate it to be involved in other important biological functions [3].

The PIEZO family of cation selective channels includes two isoforms, PIEZO1 and PIEZO2 [4]. Both PIEZO1 and PIEZO2 are directly activated by mechanical stress [5]. PIEZO1 is also activated by shear stimuli on the cell membrane [1] and a chemical agonistic compound, 2-[5-[[(2,6-Dichlorophenyl)methyl]thio]-1,3,4-thiadiazol-2-yl]-pyrazine (Yoda1) [6]. PIEZO1 is a sensor in the integrated response to bladder distention in urothelium [7] and contributes to mechanical stress-induced osteoclastogenesis in human periodontal ligament cells [8]. Moreover, PIEZO1 is involved in red blood cell function, because mutations in this gene cause dehydrated hereditary xerocytosis [9-12]. In turn, PIEZO2 is predominantly expressed in sensory tissues. In particular, it is a 
mechano-sensor in Merkel cells and plays a key role in mediating the moderate touch sensation on the skin [13-15]. Although extensive studies have been performed after PIEZO1 and PIEZO2 were found to be mechano-sensors, functional analyses of these proteins are still limited.

In the present study, we examined the possibility that PIEZO1 is involved in the regulation of synovial sarcoma cell-viability. Synovial sarcoma is a malignant neoplasm that can arise at almost any anatomic site and accounts for $10-20 \%$ of soft-tissue sarcomas in adolescents and young adults [16]. Although cytotoxic chemotherapy against synovial sarcoma with drugs such as ifosfamide and anthracyclines is potentially promising $[17,18]$, the emergence of drug resistance during the treatment is common. Therefore, novel therapeutic strategies and new cytotoxic drugs are required. Because PIEZO1 is also known as Fam38A, an integrin-interacting protein [19], we hypothesized that its dysfunction may affect cancer cell survival. Here, by employing PIEZO1 agonist Yoda1 and siRNA technology, we demonstrate that PIEZO1 is highly expressed in human synovial sarcoma SW982 cells and its knockdown affects the cell-viability.

\section{Results}

\subsection{Effects of Yoda1 on HEK-Piezo1 and SW982 Cells}

To re-examine the effectiveness of Yoda1 on the PIEZO1 channel, we applied Yoda1 to HEK cells transiently expressing human PIEZO1 (HEK-Piezo1). As shown in Figure 1A,B, the application of $0.3 \mu \mathrm{M}$ Yoda1 evoked $\mathrm{Ca}^{2+}$ response in HEK-Piezo1 cells, while it had little effect on native HEK cells (HEK-cont), where only PIEZO1 was expressed at a low level. In addition, the $\mathrm{Ca}^{2+}$ response of HEK-Piezo1 cells to Yoda1 was significantly attenuated in SBS without $\mathrm{Ca}^{2+}$ (Figure 1C), confirming that Yoda1 is an effective activator of human PIEZO1 as previously reported $[6,20]$. We next examined the effects of Yoda1 on synovial sarcoma SW982 cells. As shown in Figure 1D,E, the application of Yoda1 at a range of concentrations from 0.03 to $3 \mu \mathrm{M}$ evoked $\mathrm{Ca}^{2+}$ response in SW982 cells in a concentration-dependent manner. Moreover, the removal of $\mathrm{Ca}^{2+}$ from SBS abolished $\mathrm{Ca}^{2+}$ response to $0.3 \mu \mathrm{M}$ Yoda1 (Figure 1F), suggesting that SW982 cells highly express the PIEZO1 channel. 

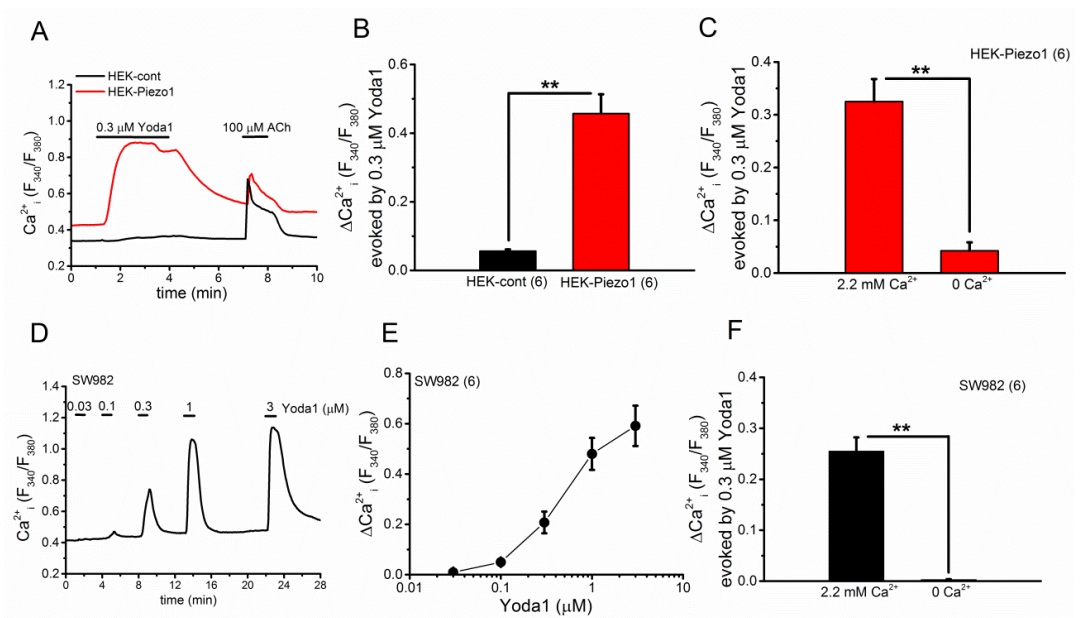

E

$\mathrm{F}$

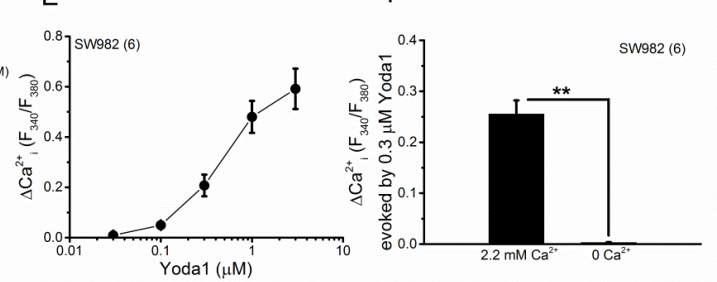

Figure 1. Effects of Yoda1 on HEK-Piezo1 (A-C) and SW982 cells (D-F). (A) A representative Ca ${ }^{2+}$ response of HEK-Piezo1 and HEK-cont cells to $0.3 \mu \mathrm{M}$ Yoda1 and $100 \mu \mathrm{M}$ Ach; (B) A summary of the peak change in $\mathrm{Ca}^{2+}$ response of HEK-Piezo1 and HEK-cont cells to Yoda1; (C) A summary of the peak evoked $\mathrm{Ca}^{2+}$ response of HEK-Piezo1 cells in the presence and absence of extracellular $\mathrm{Ca}^{2+}$ to Yoda1 $(0.3 \mu \mathrm{M})$; (D) A representative $\mathrm{Ca}^{2+}$ response of SW982 cells to a range of Yoda1 concentrations between 0.03 and $3 \mu \mathrm{M}$; (E) The peak change of $\mathrm{Ca}^{2+}$ response of SW982 cells to a range of Yoda1 concentrations; (F) A summary of the peak evoked $\mathrm{Ca}^{2+}$ response of SW982 cells in the presence and absence of extracellular $\mathrm{Ca}^{2+}$ to Yoda1 $(0.3 \mu \mathrm{M})$. Pooled data are averaged and expressed as mean $\pm \mathrm{SEM}$. Statistical significance was established using Student's $t$-test. ${ }^{* *} p<0.01$ compared with each corresponding control group. The numbers in parentheses indicate the number of independent experiments.

\subsection{PIEZO1 Channel Activation by Yoda1 and Mechanical Stress}

Because both Yoda1 and mechanical stimuli activate the PIEZO1 channel, we examined electrophysiological profiles of Yoda1-induced cation currents in HEK-Piezo1 and SW982 cells (Figures 2 and 3). In a cell-attached patch clamp configuration, where the pipette solution contained SBS with $3 \mu \mathrm{M}$ Yoda1, intrinsic channel activity was found at $-70 \mathrm{mV}(-1.55 \pm 0.08 \mathrm{pA}, n=4$, also see the histogram on the left in the inset). The application of an additional negative pressure of $20 \mathrm{~mm}$ $\mathrm{Hg}$ to the patch membrane induced a higher channel activity, whose unit current $(-1.52 \pm 0.08 \mathrm{pA}$, $n=3$, see also the histogram on the right in the inset) was similar to the intrinsic one. Figure $2 \mathrm{~B}, \mathrm{C}$ show Yoda1- and mechanical stress-sensitive channel activity against a range of holding potentials and a summary of each activity, respectively, suggesting that Yoda1 and mechanical stress both activate the PIEZO1 channel. In Figure 3, Yoda1 was applied to HEK-Piezo1 (Figure 3A,B) and SW982 cells (Figure 3C,D) under whole-cell conditions. Yoda1 effectively activated cation channel currents in HEK-Piezo1 and SW982 cells. In both cell types, the activation was largely reversible at a negative potential after the wash-out of Yoda1, whereas the activation was partially irreversible at a positive potential. In contrast, HEK-cont cells were insensitive to $10 \mu \mathrm{M}$ Yoda1 (Supplementary Figure S1B). Moreover, HEK cells transfected with a canonical human Transient Receptor Potential Channel 4 (HEK-hTRPC4) were also resistant to $3 \mu \mathrm{M}$ Yoda1, while these cells responded to $100 \mathrm{nM}$ EA, an TRPC4 agonist (Supplementary Figure S1A,B, [21]). These data strongly suggest that SW982 cells express functional PIEZO1 channels which are effectively activated by Yoda1. 
A

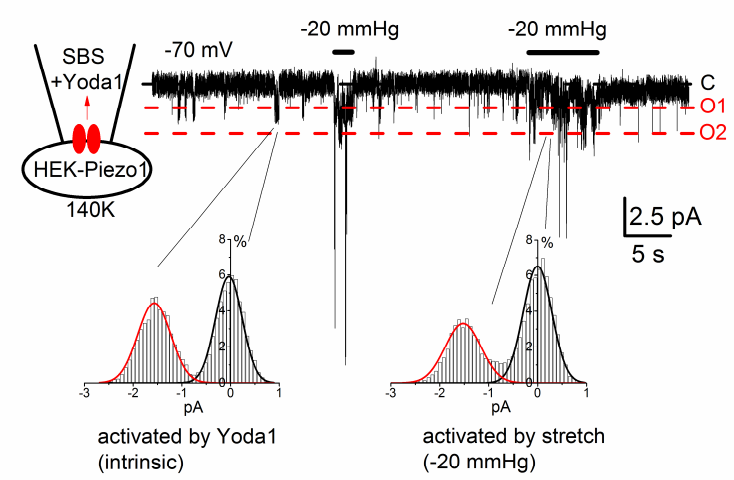

B
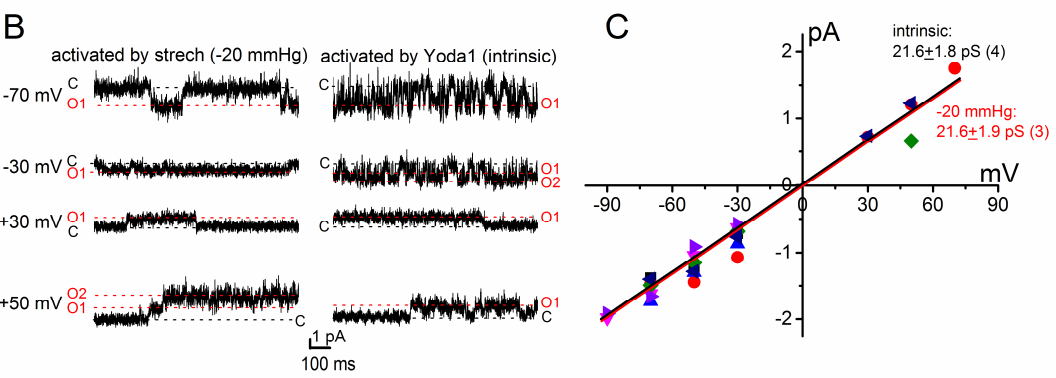

Figure 2. Comparison between Yoda1- and stretch-induced channel activities in HEK-Piezo1 cells. Channel activity was recorded in the cell-attached patch configuration (see the schematic inset and Methods and Materials in details). (A) The representative channel activity at a holding potential of $-70 \mathrm{mV}$, evoked intrinsically and induced by a negative pressure of $20 \mathrm{mmHg}$ to the patch membrane. Amplitude histograms for a 1-s period during activation of the intrinsic opening channel and stretch-induced channel, respectively, are shown in insets; $(\mathrm{B}, \mathrm{C})$ The channel activity induced by Yoda1 (intrinsic) and stretch $(-20 \mathrm{mmHg})$ compared at different holding potentials. The ' $\mathrm{C}$, ' $\mathrm{O} 1^{\prime}$, and 'O2' labels denote activity levels corresponding to both channels closing, the first channel opening, and the second channel opening, respectively. These data were obtained from two different cells; (C) The unit amplitude of each channel summarized against potentials. The numbers in parentheses indicate the number of independent experiments. 
A

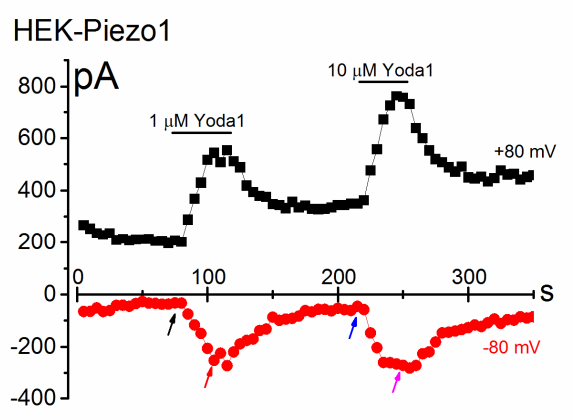

C

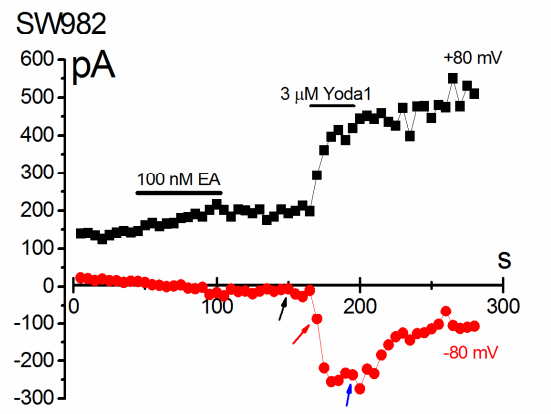

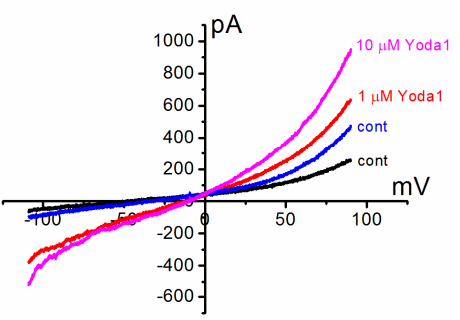

B
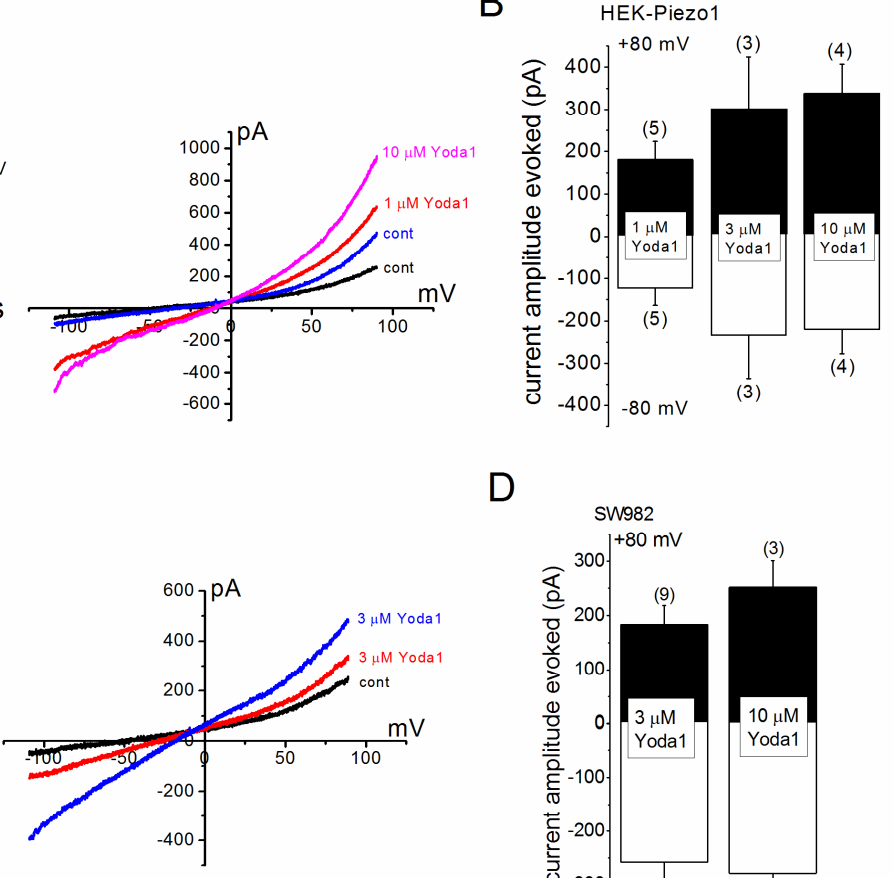

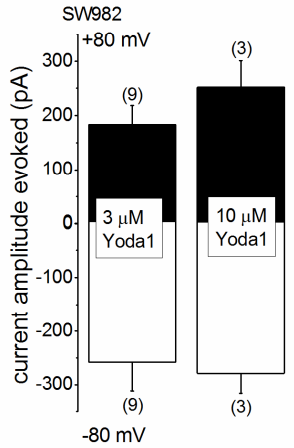

Figure 3. Yoda1-induced cation currents in HEK-Piezo1 and SW982 cells. (A,B) HEK-Piezo1 cells were voltage-clamped in whole-cell configuration mode and treated with $1 \mu \mathrm{M}$ or $10 \mu \mathrm{M}$ Yoda1. (A) Left panel: Ramp waveform pulses from -110 to $+90 \mathrm{mV}$ for $400 \mathrm{~ms}$ were applied every $5 \mathrm{~s}$ and the peak amplitude of cation currents at -80 and $+80 \mathrm{mV}$ was plotted against time. Arrows denote the time at which each I-V was detected. Right panel: A typical I-V exhibited before and after application of $1 \mu \mathrm{M}$ and $10 \mu \mathrm{M}$ Yoda1; (B) A summary of the peak amplitudes of cation currents at -80 and $+80 \mathrm{mV}$ in the presence of Yoda1; (C,D) SW982 cells were treated with Yoda1 under similar experimental conditions to HEK-Piezo1 cells. SW982 cells were exposed to EA at $100 \mathrm{nM}$ as previously reported. Pooled data are averaged and expressed as mean \pm SEM. The numbers in parentheses indicate the number of independent experiments.

\subsection{Knocking down of PIEZO1 Channel in SW982 Cells}

To test the function of PIEZO1 in synovial sarcoma, we next knocked down PIEZO1 in SW982 cells using stealth small interfering RNA (siRNA). As shown in Figure 4A, the level of PIEZO1 mRNA in SW982 cells treated with PIEZO1-specific siRNA (si-Piezo1) for $72 \mathrm{~h}$ was significantly reduced compared with sc-RNA (see also Supplementary Figure S2). SW982 cells treated with si-Piezo1 were then exposed to Yoda1 and histamine (His) while monitoring their $\mathrm{Ca}^{2+}$ responses (Figure 4B-D). Compared with SW982 cells with sc-RNA, the $\mathrm{Ca}^{2+}$ response of SW982 cells treated with si-Piezo1 to $0.3 \mu \mathrm{M}$ Yoda1 was significantly reduced (Figure $4 \mathrm{C}$ ), while the response to $100 \mu \mathrm{M}$ His was unchanged (Figure 4D). This suggests that PIEZO1 is not functional in SW982 cells treated with si-Piezo1. To use these cells, we compared the cell-viability of SW982 cells with and without functional PIEZO1. As shown in Figure 4E, PIEZO1 knockdown in SW982 cells effectively reduced cell-viability, suggesting that this protein is a functional regulator of cell-viability in SW982 synovial sarcoma cells. In contrast, Yoda1-induced activation of PIEZO1 had little effect on cell-viability. 
A

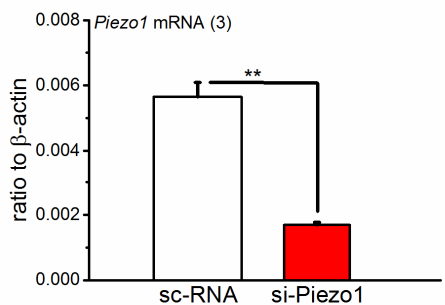

C

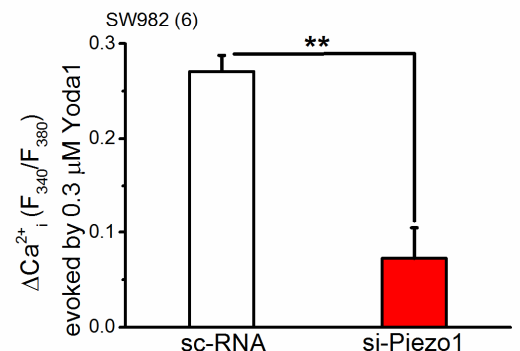

E

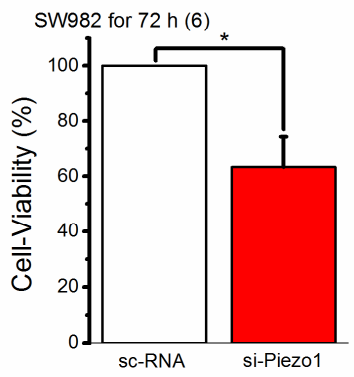

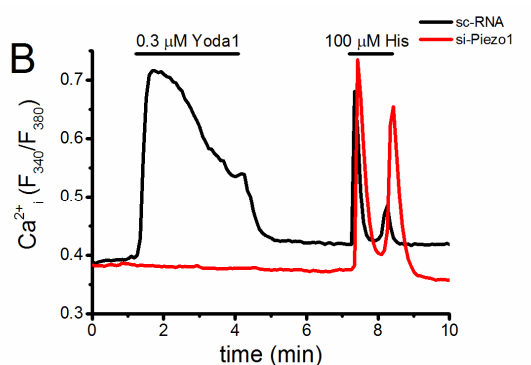

D

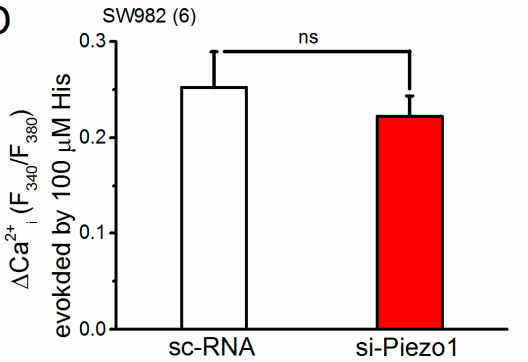

$\mathrm{F}$

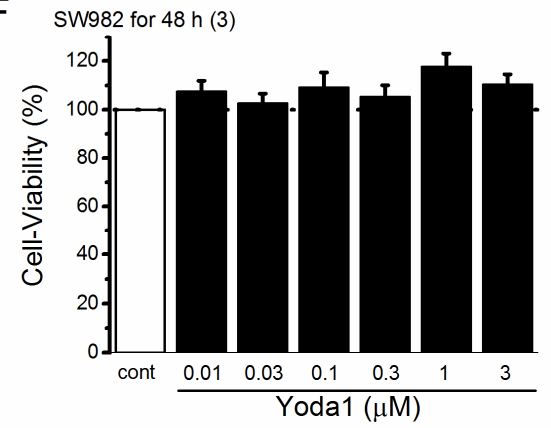

Figure 4. PIEZO1 knockdown in SW982 cells and its effect on the cell-viability. (A-D) The expression of PIEZO1 in SW982 cells was reduced by si-Piezo1 treatment for $72 \mathrm{~h}$. (A) The mRNA expression level of PIEZO1 in SW982 cells transfected with si-Piezo1 compared with that in cells transfected with stealth control siRNA (sc-RNA); (B) A representative $\mathrm{Ca}^{2+}$ response to Yoda1 $(0.3 \mu \mathrm{M})$ and histamine (His; $100 \mu \mathrm{M})$ in SW982 cells treated with either si-Piezo1 or sc-RNA; (C,D). A summary of the peak change $\left(\triangle \mathrm{Ca}^{2+}\right)$ in cells treated with either si-Piezo1 or sc-RNA; (E) The effect of PIEZO1 knockdown on SW982 cell-viability; (F) SW982 cell-viability after treatment with Yoda1 at a concentration range between 0.01 and $3 \mu \mathrm{M}$ for $48 \mathrm{~h}$. Pooled data are averaged and expressed as mean \pm SEM. Statistical significance was established using Student's $t$-test. ${ }^{*} p<0.05$ and ${ }^{* *} p<0.01$ compared with each corresponding control group. 'ns' indicates no significance. The numbers in parentheses indicate the number of independent experiments.

\section{Discussion}

In this study, we found that synovial sarcoma SW982 cells express PIEZO1, which is effectively activated by Yoda1 in a concentration-dependent manner. Knocking down PIEZO1 expression reduced SW982 cell-viability as well as Yoda1-induced $\mathrm{Ca}^{2+}$ response, suggesting that PIEZO1 is a potential regulator of cancer cell-viability.

PIEZO1 is a mechano-sensor that is effectively activated by a chemical agonist Yoda1 [6]. Yoda1 was shown to substantially activate mouse Piezo1 in red blood cells [22] and vascular endothelial cells [20]. In the present study, we showed that Yoda1 evoked $\mathrm{Ca}^{2+}$ responses in HEK-Piezo1 and SW982 cells, both of which were abolished in the absence of extracellular $\mathrm{Ca}^{2+}$. In addition, Yoda1 caused the activation of cation channel currents in both cell types, strongly suggesting that synovial sarcoma SW982 cells express functional PIEZO1. Interestingly, we found the apparent $\mathrm{EC}_{50}$ of Yoda1 against SW982 cells to be less than $1 \mu \mathrm{M}$ (Figure 1E), while the apparent EC $_{50}$ for human PIEZO1 expressed in HEK cells was reported to be $26.6 \mu \mathrm{M}$ [6]. The reason for this discrepancy is not clear, but the different experimental 
conditions may affect the biological response to Yoda1. Consistent with our results, Yoda1 at less than $1 \mu \mathrm{M}$ effectively activated Piezo1 in mouse vascular endothelial cells [20]. Because Yoda1 is highly lipophilic [6], it is possible that this physical property affects experimental assays. Nevertheless, Yoda1 is a useful chemical activator for PIEZO1. The conductance of Yoda1-induced intrinsic channel was identical to that of mechanical stress sensitive channel (21.6 pS, Figure $2 \mathrm{C}$ ): Yoda1 at $3 \mu \mathrm{M}$ and $10 \mu \mathrm{M}$ had little effect on HEK-hTRPC4 cells and HEK-cont cells (Supplementary Figure S1).

It has been shown that mechanical stress affects cancer cell migration and invasion [23]. Moreover, the blockade of mechano-sensitive channels by tarantula toxin GsMTx-4 inhibited the motility of human breast cancer cell line MCF-7 [24]. Because PIEZO1 is highly expressed in MCF-7 cells and is substantially inhibited by GsMTx-4, it is proposed that PIEZO1 is a potential regulator of cancer cell motility. In contrast, the loss of PIEZO1 expression caused increased cell migration and metastasis in lung cancer cells [25]. In the present study, the knockdown of PIEZO1 significantly reduced the cell-viability of SW982 cells. However, it is not clear if channel activation itself plays a key role in the regulation of cell-viability. In fact, Yoda1-induced activation of PIEZO1 had little effect on SW982 cell-viability, suggesting that PIEZO1 channel function is not involved in this process. The deletion of PIEZO1 reduces cell adhesion [19] and thus may affect cell-viability.

Our recent study has demonstrated that the activation of heteromeric TRPC 4 and TRPC1 (TRPC4/C1) causes a potent cytotoxic effect on SW982 cells mediated via $\mathrm{Na}^{+}$loading [21], suggesting that heteromeric TRPC4/C1 is a promising target of anti-tumor agents against synovial sarcoma. Because cell-viability was effectively inhibited in SW982 cells lacking functional PIEZO1 in the present study, PIEZO1 is a potential novel target against synovial sarcoma. In addition, it has been shown that PIEZO1 activation by cell stretch induces the apoptosis of human chondrocytes in osteoarthritis [26]. PIEZO1 is ubiquitously expressed in neuronal and non-neuronal organs. A global loss of Piezo1 in mouse is lethal during mid-gestation because of disrupted development of vasculature [1,2]. A smooth muscle cell-specific loss of PIEZO1 causes the deficit of arterial remodeling upon hypertension [27]. Moreover, endothelial PIEZO1 regulates blood pressure in mice both with [20] and without exercise [28]. Therefore, the functional significance of application anti-PIEZO1 agents is rather complicated [3] and further extensive studies are required.

\section{Materials and Methods}

\subsection{Reagents}

The following reagents were used: 2-[5-[[(2,6-Dichlorophenyl)methyl]thio]-1,3,4-thiadiazol-2 -yl]-pyrazine (Yoda1, Tocris Bioscience, Bristol, UK), (-)englerin-A (EA, AppliChem, Darmstadt, Germany), acetylcholine (ACh, Wako, Osaka, Japan), and histamine (His, Wako). Each reagent was dissolved in the vehicle recommended by the manufacturer.

\subsection{Cell Culture}

Human synovial sarcoma SW982 (SW982, American Type Culture Collection, Manassas, VA, USA) and human embryonic kidney 293 cell lines (HEK, Health Science Research Resources Bank, Osaka, Japan) were maintained in culture media recommended by the manufacturers [21]. All culture media were supplemented with 10\% heat-inactivated FCS (GIBCO, Waltham, MA, USA), streptomycin $(100 \mu \mathrm{g} / \mathrm{mL}$, Meiji Seika Pharma Co., Ltd., Tokyo, Japan), and penicillin G (100 U/mL, Meiji Seika Pharma Co., Ltd.).

\subsection{Recombinant Expression of PIEZO1 in HEK Cells}

Partially confluent HEK cells (40-60\% confluency) were transfected with the pcDNA3.1 (for $\mathrm{Ca}^{2+}$ measurements) and pIRES2-AcGFP1 (for patch-clamp experiments) plasmids containing human PIEZO1 and TRPC4, respectively, using Lipofectamine 3000 (ThermoFisher Scientific, Yokohama, Japan). All constructs were verified by sequencing. Cells were used in experiments within $48 \mathrm{~h}$ after transfection. 


\subsection{Quantitative PCR and RT-PCR}

Real-time quantitative PCR was performed with SYBR Green chemistry on a Thermal Cycler Dice Real Time System (Takara Bio, Inc., Kusatsu, Japan) as described previously [21]. Transcriptional quantification of gene products was performed relative to $\beta$-ACTIN. Each cDNA sample was tested in triplicate. The program used for quantitative PCR amplification consisted of a $30 \mathrm{~s}$ activation of Ex Taq ${ }^{\mathrm{TM}}$ DNA polymerase at $95{ }^{\circ} \mathrm{C}$, a $15 \mathrm{~s}$ denaturation step at $95{ }^{\circ} \mathrm{C}$, a $60 \mathrm{~s}$ annealing and extension step at $60{ }^{\circ} \mathrm{C}$ (for 45 cycles), and a dissociation step (15 s at $95{ }^{\circ} \mathrm{C}, 30 \mathrm{~s}$ at $60{ }^{\circ} \mathrm{C}$, and $15 \mathrm{~s}$ at $95^{\circ} \mathrm{C}$ ). The oligonucleotide sequences of primers specific for human PIEZO1 and $\beta$-ACTIN are: TAGCCATTACTACCTGCACGTC (forward), TGCGGTGAAAGTCAATGCTC (reverse) and ACCGAGCGCGGCTACA (forward), CAGCCGTGGCCATCTCTT (reverse), respectively. RT-PCR amplification for PIEZO1 and $\beta$-ACTIN was performed as followings. The thermal cycler program used for PCR amplification included a $30 \mathrm{~s}$ denaturation step at $94{ }^{\circ} \mathrm{C}$, a $30 \mathrm{~s}$ annealing step at $55{ }^{\circ} \mathrm{C}$, and a $30 \mathrm{~s}$ primer extension step at $72{ }^{\circ} \mathrm{C}$ for 29 and 22 cycles for PIEZO11 and $\beta$-ACTIN, respectively, using an ABI 2720 thermal cycler (Applied Biosystems, Foster City, CA, USA). The amplified products were separated on $1.5 \%$ agarose gels in Tris acetate/EDTA buffer, visualized with $1 \mu \mathrm{g} / \mathrm{mL}$ ethidium bromide, and assessed on FAS III (TOYOBO, Osaka, Japan).

\subsection{Patch-Clamp Experiments}

Whole-cell current and single-channel recording experiments were performed as described previously $[29,30]$. The resistance of pipettes was 3-5 M $\Omega$ when filled with pipette solution. A $\mathrm{Cs}^{+}$ rich pipette solution containing $110 \mathrm{mM}$ Cs-aspartate, $30 \mathrm{mM} \mathrm{CsCl}, 1 \mathrm{mM} \mathrm{MgCl} 2,10 \mathrm{mM}$ HEPES, $1 \mathrm{mM}$ EGTA, and $2 \mathrm{mM} \mathrm{Na}{ }_{2}$ ATP was adjusted to $\mathrm{pH} 7.2$ with $\mathrm{CsOH}$. Membrane currents and voltage signals were amplified with an EPC-800 amplifier (HEKA, Lambrechit, Germany) and digitized at $10 \mathrm{KHz}$ using an analogue-digital converter (PCI6229, National Instruments Japan, Tokyo, Japan) driven by WinWCPV4.5 and WINEDR3.38 for data acquisition and analysis for whole-cell currents and cell-attached single channel currents, respectively (developed by John Dempster, University of Strathclyde, Glasgow, UK). The liquid junction potential between the pipette and bath solutions $(-10 \mathrm{mV})$ was corrected when the aspartate rich pipette solution was used. A ramp voltage protocol from $-110 \mathrm{mV}$ to $+90 \mathrm{mV}$ for $400 \mathrm{~ms}$ was applied every $5 \mathrm{~s}$ from a holding potential of $-10 \mathrm{mV}$. A leak current component was not subtracted from the recorded currents. A standard HEPES-buffered bathing solution (SBS: $137 \mathrm{mM} \mathrm{NaCl}, 5.9 \mathrm{mM} \mathrm{KCl}, 2.2 \mathrm{mM} \mathrm{CaCl}_{2}, 1.2 \mathrm{mM} \mathrm{MgCl} 2,14 \mathrm{mM}$ glucose, 10 mM HEPES, adjusted to $\mathrm{pH} 7.4$ with $\mathrm{NaOH}$ ) was used. In the cell-attached patch experiments, the pipette contained SBS supplemented with $10 \mathrm{mM}$ TEA. To set a resting membrane potential around $0 \mathrm{mV}$ in the cell-attached patch configuration, high $\mathrm{K}^{+}$bathing solution was used $(140 \mathrm{mM} \mathrm{KCl}, 2.2 \mathrm{mM}$ $\mathrm{CaCl}_{2}, 1.2 \mathrm{mM} \mathrm{MgCl}_{2}, 14 \mathrm{mM}$ glucose, $10 \mathrm{mM}$ HEPES, adjusted to $\mathrm{pH} 7.4$ with $\mathrm{NaOH}$ ). All experiments were performed at $25 \pm 1^{\circ} \mathrm{C}$.

\subsection{Measurement of $\mathrm{Ca}^{2+}$ Fluorescence Ratio}

Cells were loaded with $10 \mu \mathrm{M}$ Fura2-AM (Dojindo, Kumamoto, Japan) in SBS for 30 min at 24-26 ${ }^{\circ} \mathrm{C}$, superfused with SBS for $10 \mathrm{~min}$, and Fura-2 fluorescence signals were measured at $0.1 \mathrm{~Hz}$ using the Argus/HisCa imaging system (Hamamatsu Photonics, Hamamatsu, Japan) driven by Imagework Bench 6.0 (INDEC Medical Systems, Santa Clara, CA, USA). In each analysis, the whole cell area was chosen as the region of interest to average the fluorescence ratio.

\subsection{Specific Knockdown of PIEZO1 by RNA Interference}

The sequence of the stealth short interfering RNA (si-RNA) duplex oligonucleotides against human PIEZO1 (si-Piezo1, Dharmacon, part of GE Healthcare, Lafayette, CO, USA) is 5'-GCCU CGUGGUCUACAAGAUTT-3' ${ }^{\prime}$ for the sense strand and 5'-AUCUUGUAGACCACGAGGCTT-3' for the antisense strand. As a negative control for the si-RNA treatment, Non-Targeting siRNA \#1 (sc-RNA, 
Dharmacon) was used. The cells grown in a 35-mm dish or a 24-well plate were washed with fresh culture medium without antibiotics $3 \mathrm{~h}$ prior to transfection. The si-Piezo1 or sc-RNA ( $20 \mu \mathrm{M}, 2 \mu \mathrm{L}$ for the 35-mm dish and $0.5 \mu \mathrm{L}$ for the 24-well plate, respectively) and Lipofectamine RNAiMAX (2.5 $\mu \mathrm{L}$ for the 35-mm dish and $0.63 \mu \mathrm{L}$ for the 24-well plate, respectively; Invitrogen) were diluted in $250 \mu \mathrm{L}$ (35-mm dish) and $62.5 \mu \mathrm{L}$ (24-well plates) Opti-MEM (Invitrogen), respectively, mixed together and incubated for $20 \mathrm{~min}$ at room temperature for complex formation. The entire mixture was added to the cells, resulting in a final concentration of $20 \mathrm{nM}$ for both si-Piezo1 and sc-RNA. The cells were incubated for $72-96 \mathrm{~h}$ in a $\mathrm{CO}_{2}$ chamber.

\subsection{WST-1 Cell-Viability Assay}

Cells were seeded onto 24-well plate $24 \mathrm{~h}$ prior to WST-1 measurements $\left(1 \times 10^{4}\right.$ SW982 cells were used for analysis). The cell-viability reagent WST-1 (Roche Applied Science, Penzberg, Germany) was used in accordance to the manufacturer's instructions [21]. Reduction of the tetrazolium salt WST-1 to formazan by mitochondrial dehydrogenases was determined by measuring absorbance at $450 \mathrm{~nm}$ (DXT880 Multimode Detector, Beckman Coulter, Brea, CA, USA). Cell death resulting in the loss of mitochondrial dehydrogenase activity was inferred from a decrease in the yield of this reaction. Background absorbance at the reference wavelength $620 \mathrm{~nm}$ was subtracted. Each sample was tested in duplicate or triplicate and pooled data were summarized across independent experiments.

\subsection{Statistical Analyses}

Data are expressed as the mean \pm SEM. Statistical significance between two groups and across multiple groups was examined using unpaired Student's $t$-test and ANOVA test, respectively, both two-tailed (Origin J9.1, LightStone, Tokyo, Japan). For all tests, $p$ values below 0.05 were considered statistically significant.

\section{Conclusions}

Our results provide new insights into PIEZO1 function showing that this mechno-sensing channel is highly expressed in synovial sarcoma SW982 cells and can regulate their cell-viability. The molecular mechanisms underlying the anti cell-viability in synovial sarcoma without PIEZO1 are yet to be elucidated and potentially involve the inhibition of cell adhesion.

Supplementary Materials: The following are available online at http:/ /www.mdpi.com/1422-0067/19/5/1452/ s1, Figure S1: Yoda1 has no effect on membrane currents in HEK-hTRPC4 and HEK-cont cells. (A) HEK-hTRPC4 cells were voltage-clamped in whole-cell configuration mode and treated with $3 \mu \mathrm{M}$ Yoda1. After the wash-out of Yoda1, the cells were exposed to $100 \mathrm{nM}$ EA. Left panel: Ramp waveform pulses from -110 to $+90 \mathrm{mV}$ for $400 \mathrm{~ms}$ were applied every $5 \mathrm{~s}$ and the peak amplitude of membrane currents at -80 and $+80 \mathrm{mV}$ was plotted against time. Arrows denote the time at which each I-V was detected. Right panel: A typical I-V exhibited before and after the application of $3 \mu \mathrm{M}$ Yoda1, and before and after the application of $100 \mathrm{nM}$ EA. (B) A summary of the peak amplitudes of membrane currents evoked at -80 and $+80 \mathrm{mV}$ in the presence of $3 \mu \mathrm{M}$ Yoda1 and $100 \mathrm{nM}$ EA in HEK-hTRPC4 cells, and $10 \mu \mathrm{M}$ Yoda1 in HEK-cont cells. Pooled data were averaged and expressed as mean \pm SEM. The numbers in parentheses indicate the number of independent experiments. Figure S2: The mRNA expression of PIEZO1 and $\beta$-ACTIN was determined with RT-PCR in SW982 cells treated with sc-RNA and si-Piezo1. Three independent samples were tested.

Author Contributions: K.M. contributed generated figures, analyzed and conceptualized the data, and performed the patch-clamp experiments supported by H.S. and N.H. T.S. performed the calcium measurement studies that initially identified the Yoda1-response of SW982 cells, and the WST-1 assay. N.H. designed primers for PCR experiments. Y.M. generated all clones used. All authors commented on the manuscript. K.M. designed and initiated the project, acquired research funds, led and coordinated the project, interpreted the data, and wrote the paper.

Acknowledgments: This work was supported by a Grant-in-Aid for Scientific Research to K.M. (26460349) from the Japan Society for the Promotion of Science. We thank J. Dempster (University of Strathclyde, UK) for developing the electrophysiology software (WinWCPV4.5 and WinEDRV3.38).

Conflicts of Interest: The authors declare no conflict of interest. 


\section{References}

1. Li, J.; Hou, B.; Tumova, S.; Muraki, K.; Bruns, A.; Ludlow, M.J.; Sedo, A.; Hyman, A.J.; McKeown, L.; Young, R.S.; et al. Piezo1 integration of vascular architecture with physiological force. Nature 2014, 515, $279-282$. [CrossRef] [PubMed]

2. Ranade, S.S.; Qiu, Z.; Woo, S.H.; Hur, S.S.; Murthy, S.E.; Cahalan, S.M.; Xu, J.; Mathur, J.; Bandell, M.; Coste, B.; et al. Piezo1, a mechanically activated ion channel, is required for vascular development in mice. Proc. Natl. Acad. Sci. USA 2014, 111, 10347-10352. [CrossRef] [PubMed]

3. Wu, J.; Lewis, A.H.; Grandl, J. Touch, Tension, and Transduction-The Function and Regulation of Piezo Ion Channels. Trends Biochem. Sci. 2017, 42, 57-71. [CrossRef] [PubMed]

4. Coste, B.; Mathur, J.; Schmidt, M.; Earley, T.J.; Ranade, S.; Petrus, M.J.; Dubin, A.E.; Patapoutian, A. Piezo1 and Piezo2 are essential components of distinct mechanically activated cation channels. Science 2010, 330, 55-60. [CrossRef] [PubMed]

5. Coste, B.; Xiao, B.; Santos, J.S.; Syeda, R.; Grandl, J.; Spencer, K.S.; Kim, S.E.; Schmidt, M.; Mathur, J.; Dubin, A.E.; et al. Piezo proteins are pore-forming subunits of mechanically activated channels. Nature 2012, 483, 176-181. [CrossRef] [PubMed]

6. Syeda, R.; Xu, J.; Dubin, A.E.; Coste, B.; Mathur, J.; Huynh, T.; Matzen, J.; Lao, J.; Tully, D.C.; Engels, I.H.; et al. Chemical activation of the mechanotransduction channel Piezo1. Elife 2015, 4, e07369. [CrossRef] [PubMed]

7. Miyamoto, T.; Mochizuki, T.; Nakagomi, H.; Kira, S.; Watanabe, M.; Takayama, Y.; Suzuki, Y.; Koizumi, S.; Takeda, M.; Tominaga, M. Functional role for Piezo1 in stretch-evoked $\mathrm{Ca}^{2+}$ influx and ATP release in urothelial cell cultures. J. Biol. Chem. 2014, 289, 16565-16575. [CrossRef] [PubMed]

8. Jin, Y.; Li, J.; Wang, Y.; Ye, R.; Feng, X.; Jing, Z.; Zhao, Z. Functional role of mechanosensitive ion channel Piezo1 in human periodontal ligament cells. Angle Orthod. 2015, 85, 87-94. [CrossRef] [PubMed]

9. Andolfo, I.; Alper, S.L.; De Franceschi, L.; Auriemma, C.; Russo, R.; De Falco, L.; Vallefuoco, F.; Esposito, M.R.; Vandorpe, D.H.; Shmukler, B.E.; et al. Multiple clinical forms of dehydrated hereditary stomatocytosis arise from mutations in PIEZO1. Blood 2013, 121, 3925-3935. [CrossRef] [PubMed]

10. Bae, C.; Gnanasambandam, R.; Nicolai, C.; Sachs, F.; Gottlieb, P.A. Xerocytosis is caused by mutations that alter the kinetics of the mechanosensitive channel PIEZO1. Proc. Natl. Acad. Sci. USA 2013, 110, E1162-E1168. [CrossRef] [PubMed]

11. Albuisson, J.; Murthy, S.E.; Bandell, M.; Coste, B.; Louis-Dit-Picard, H.; Mathur, J.; Feneant-Thibault, M.; Tertian, G.; de Jaureguiberry, J.P.; Syfuss, P.Y.; et al. Dehydrated hereditary stomatocytosis linked to gain-of-function mutations in mechanically activated PIEZO1 ion channels. Nat. Commun. 2013, 4, 1884. [PubMed]

12. Zarychanski, R.; Schulz, V.P.; Houston, B.L.; Maksimova, Y.; Houston, D.S.; Smith, B.; Rinehart, J.; Gallagher, P.G. Mutations in the mechanotransduction protein PIEZO1 are associated with hereditary xerocytosis. Blood 2012, 120, 1908-1915. [CrossRef] [PubMed]

13. Ranade, S.S.; Woo, S.H.; Dubin, A.E.; Moshourab, R.A.; Wetzel, C.; Petrus, M.; Mathur, J.; Begay, V.; Coste, B.; Mainquist, J.; et al. Piezo2 is the major transducer of mechanical forces for touch sensation in mice. Nature 2014, 516, 121-125. [CrossRef] [PubMed]

14. Woo, S.H.; Ranade, S.; Weyer, A.D.; Dubin, A.E.; Baba, Y.; Qiu, Z.; Petrus, M.; Miyamoto, T.; Reddy, K.; Lumpkin, E.A.; et al. Piezo2 is required for Merkel-cell mechanotransduction. Nature 2014, 509, $622-626$. [CrossRef] [PubMed]

15. Ikeda, R.; Gu, J.G. Piezo2 channel conductance and localization domains in Merkel cells of rat whisker hair follicles. Neurosci. Lett. 2014, 583, 210-215. [CrossRef] [PubMed]

16. Herzog, C.E. Overview of sarcomas in the adolescent and young adult population. J. Pediatr. Hematol. Oncol. 2005, 27, 215-218. [CrossRef] [PubMed]

17. Spurrell, E.L.; Fisher, C.; Thomas, J.M.; Judson, I.R. Prognostic factors in advanced synovial sarcoma: An analysis of 104 patients treated at the Royal Marsden Hospital. Ann. Oncol. 2005, 16, 437-444. [CrossRef] [PubMed]

18. Al-Hussaini, H.; Hogg, D.; Blackstein, M.E.; O'Sullivan, B.; Catton, C.N.; Chung, P.W.; Griffin, A.M.; Hodgson, D.; Hopyan, S.; Kandel, R.; et al. Clinical features, treatment, and outcome in 102 adult and pediatric patients with localized high-grade synovial sarcoma. Sarcoma 2011. [CrossRef] [PubMed] 
19. McHugh, B.J.; Buttery, R.; Lad, Y.; Banks, S.; Haslett, C.; Sethi, T. Integrin activation by Fam38A uses a novel mechanism of R-Ras targeting to the endoplasmic reticulum. J. Cell Sci. 2010, 123 Pt 1, 51-61. [CrossRef] [PubMed]

20. Rode, B.; Shi, J.; Endesh, N.; Drinkhill, M.J.; Webster, P.J.; Lotteau, S.J.; Bailey, M.A.; Yuldasheva, N.Y.; Ludlow, M.J.; Cubbon, R.M.; et al. Piezo1 channels sense whole body physical activity to reset cardiovascular homeostasis and enhance performance. Nat. Commun. 2017, 8, 350. [CrossRef] [PubMed]

21. Muraki, K.; Ohnishi, K.; Takezawa, A.; Suzuki, H.; Hatano, N.; Muraki, Y.; Hamzah, N.; Foster, R.; Waldmann, H.; Nussbaumer, P.; et al. $\mathrm{Na}^{+}$entry through heteromeric TRPC4/C1 channels mediates (-)Englerin A-induced cytotoxicity in synovial sarcoma cells. Sci. Rep. 2017, 7, 16988. [CrossRef] [PubMed]

22. Cahalan, S.M.; Lukacs, V.; Ranade, S.S.; Chien, S.; Bandell, M.; Patapoutian, A. Piezo1 links mechanical forces to red blood cell volume. Elife 2015, 4, e07370. [CrossRef] [PubMed]

23. Tse, J.M.; Cheng, G.; Tyrrell, J.A.; Wilcox-Adelman, S.A.; Boucher, Y.; Jain, R.K.; Munn, L.L. Mechanical compression drives cancer cells toward invasive phenotype. Proc. Natl. Acad. Sci. USA 2012, 109, 911-916. [CrossRef] [PubMed]

24. Li, C.; Rezania, S.; Kammerer, S.; Sokolowski, A.; Devaney, T.; Gorischek, A.; Jahn, S.; Hackl, H.; Groschner, K.; Windpassinger, C.; et al. Piezo1 forms mechanosensitive ion channels in the human MCF-7 breast cancer cell line. Sci. Rep. 2015, 5, 8364. [CrossRef] [PubMed]

25. McHugh, B.J.; Murdoch, A.; Haslett, C.; Sethi, T. Loss of the integrin-activating transmembrane protein Fam38A (Piezo1) promotes a switch to a reduced integrin-dependent mode of cell migration. PLoS ONE 2012, 7, e40346. [CrossRef] [PubMed]

26. Li, X.F.; Zhang, Z.; Chen, Z.K.; Cui, Z.W.; Zhang, H.N. Piezo1 protein induces the apoptosis of human osteoarthritis-derived chondrocytes by activating caspase-12, the signaling marker of ER stress. Int. J. Mol. Med. 2017, 40, 845-853. [CrossRef] [PubMed]

27. Retailleau, K.; Duprat, F.; Arhatte, M.; Ranade, S.S.; Peyronnet, R.; Martins, J.R.; Jodar, M.; Moro, C.; Offermanns, S.; Feng, Y.; et al. Piezo1 in Smooth Muscle Cells Is Involved in Hypertension-Dependent Arterial Remodeling. Cell Rep. 2015, 13, 1161-1171. [CrossRef] [PubMed]

28. Wang, S.; Chennupati, R.; Kaur, H.; Iring, A.; Wettschureck, N.; Offermanns, S. Endothelial cation channel PIEZO1 controls blood pressure by mediating flow-induced ATP release. J. Clin. Investig. 2016, 126, 4527-4536. [CrossRef] [PubMed]

29. Suzuki, H.; Hatano, N.; Muraki, Y.; Itoh, Y.; Kimura, S.; Hayashi, H.; Onozaki, K.; Ohi, Y.; Haji, A.; Muraki, K. The NADPH oxidase inhibitor diphenyleneiodonium activates the human TRPA1 nociceptor. Am. J. Physiol. Cell Physiol. 2014, 307, C384-C394. [CrossRef] [PubMed]

30. Muraki, K.; Sekine, T.; Ando, Y.; Suzuki, H.; Hatano, N.; Hirata, T.; Muraki, Y. An environmental pollutant, 9,10-phenanthrenequinone, activates human TRPA1 via critical cysteines 621 and 665. Pharmacol. Res. Perspect. 2017, 5, e00342. [CrossRef] [PubMed]

(C) 2018 by the authors. Licensee MDPI, Basel, Switzerland. This article is an open access article distributed under the terms and conditions of the Creative Commons Attribution (CC BY) license (http://creativecommons.org/licenses/by/4.0/). 